\title{
The Opportunity Cost as a Critical Determinant Factor of the Cultural Heritage Monuments' Valuation: A Modified Contingent Valuation Method
}

\author{
Odysseas Kopsidas \\ Department of Industrial Management and Technology, University of Piraeus, Piraeus 18534, Greece
}

\begin{abstract}
The subject of this study, which involves two surveys, is to estimate externalities created round a cultural heritage preservation site by means of a CVM (Contingent Valuation Method). The first survey was conducted for the ruins of ancient "Diolkos" located in Isthmus of Corinth, Greece using a sample of 200 soldiers. The second survey was conducted for the ancient theater of Lefkada, using a sample of 100 tourists and locals. The results have been analyzed with Logit model regression. The findings show that willingness to pay (or participate) is strongly affected by opportunity cost and awareness of the site's history. Further, income level and education level play a critical role in developing volunteering activity.
\end{abstract}

Key words: CVM (Contingent Valuation Method), WTP (Willingness To Pay), WTA (Willingness To Accept), externalities, cultural heritage, Diolkos.

\section{Introduction}

The economic valuation of cultural heritage remains a scientific challenge. Most studies estimate the economic effect as an external benefit or as a source of tourist attraction. The first application of the CVM (Contingent Valuation Method) in the field of cultural (non-market) goods dates back to the 1980s (Throsby and Withers, 1983). Since then many studies in literature applied, validated and optimized the CVM for historical buildings [1], museums [2], archaeological sites [3], tourism economics [4] and cultural goods [5].

Although the CVM is based basically on subjective opinions, the main attempting is to acquire objectivity by extracting attitude and information from a stratified representative sample of interviewees. Participants are asked by means of a questionnaire to assign a value on a non-marketable good or an externality (considered as "transaction spillover" by laissez-faire economists like Milton Friedman and Friedrich Hayek).

Corresponding author: Odysseas Kopsidas, Ph.D., research fields: public economics.
The evaluation of a benefit or a cost is not related to market values. The aim of the CVM is two-fold. Firstly, the CVM tries to create a hypothetical market in which participants may state their maximum WTP (Willingness To Pay) for a group of special public goods, through responses to the questionnaires. Secondly, the CMV applies to correspond to the minimum monetary amount which an individual would accept as compensation in order to deny any use of this special public good/service-WTA (Willingness To Accept) [6]. A single direct link to personal income may not reflect adequately the value of a monument; in many societies, for instance, cultural heritage of global significance (e.g., Acropolis in Athens, Greece) is traditionally linked to higher management levels, such as the state. In other cases, the interviewees might not agree with the questionnaire statements. Lo and Jim [7] have recently addressed these issues that are usually manifest as protest responses, i.e., zero or low WTP.

In effect, opportunity cost could be a multifaceted variable that adds complexity to a survey and could yield inconclusive results. When replaced with 
voluntary work, the main answer that a researcher has to extract from questionnaires is the level of the opportunity cost of a day of a voluntary work for every single participant. In present study, the authors used a different WTP approach: the interviewees were asked for voluntary participation in a restoration of Diolkos monuments in ancient Corinth in order to estimate the maximum time (measured in labor days) which volunteers are willing to spend. The main advantage of the present study is that the opportunity cost of all interviewees tends to be zero because they are fulfilling their military obligation ${ }^{1}$. Trough a sample selection from this population, the ceteris paribus condition tends to fulfill completely. Thus, this survey is not a formal application of the WTP method but it is actually a Willingness To Participate "WTPar" research. The results have been compared with a traditional WTP survey, regarding the excavation and restoration of the ancient theatre of Lefkada island in Greece. Although this study firstly looks not comparable, in fact they are able to lead to important results. More specificly, participants in both samples come from different areas of Greece since they are soldiers (Diolkos survey) and mostly tourists (Lefkada survey).

The objective aim of this paper is to examine the effect of opportunity cost in indirect economic valuation of these special public goods through the supply of voluntary labor. In addition, the main purpose of this study is to reveal useful information about a research area with no scientific activity which is the economic valuation of a monument of cultural heritage in population with almost zero opportunity cost. Moreover, this study is in the area of CVM, volunteering activity and cultural heritage. Consequently, in this paper, an effort of economic valuation of a monument of cultural heritage through a

\footnotetext{
${ }^{1}$ Military service is an obligation for every man in Greece, where they are trained for nine months. During this period they are not allowed to work or to participate in other profitable activities.
}

modified CVM, in order to extract the function of the volunteering supply of labor has been made. This study structures as follows. In Section 2, some brief information is presented for each involved monument of cultural heritage. In Section 3, methodology, data collection approaches and information about each treatment are presented.

\section{Study Areas}

It is common knowledge that the history of a monument is the main motivation of the volunteering aiming to its restoration/excavation. The volunteering activity is a part of the social capital and as a result, the history of a monument of cultural heritage benefits the whole society. In Sub-sections 2.1 and 2.2, some historical information about the two involved monuments is given.

\section{1 "Diolkos" Survey}

"Diolkos" was an ancient paved pathway which connects Corinthian and Saronic gulfs in Greece (Fig. 1). The construction of "Diolkos" dates back to 7th century B.C. by a tyrant of Corinth named Periandros in order to save transportation cost and time. For approximately 1,500 years many thousands of ships avoided the dangerous circumnavigation of Peloponnese and at the same time, the Corinthians earned huge income by tolls of passing. Diolkos was buried for many years until 1956 while the excavation was started [8]. A long part of "Diolkos" is passing through a military area which was the main motivation for the present study, since the sample selection would be effective.

Lefkada was founded as a colony of the Corinthians at the end of the 7th century B.C. Thanks to its strategic position on the north-eastern coast of the island, which allowed it to control the sea routes in the Ionian Sea, it became a major commercial and economic center of the ancient world. Plenty of ancient buildings and materials are visible in the area of Koulmos. Knowledge of the ancient theater of Lefkada was non-existent, because it has never been 

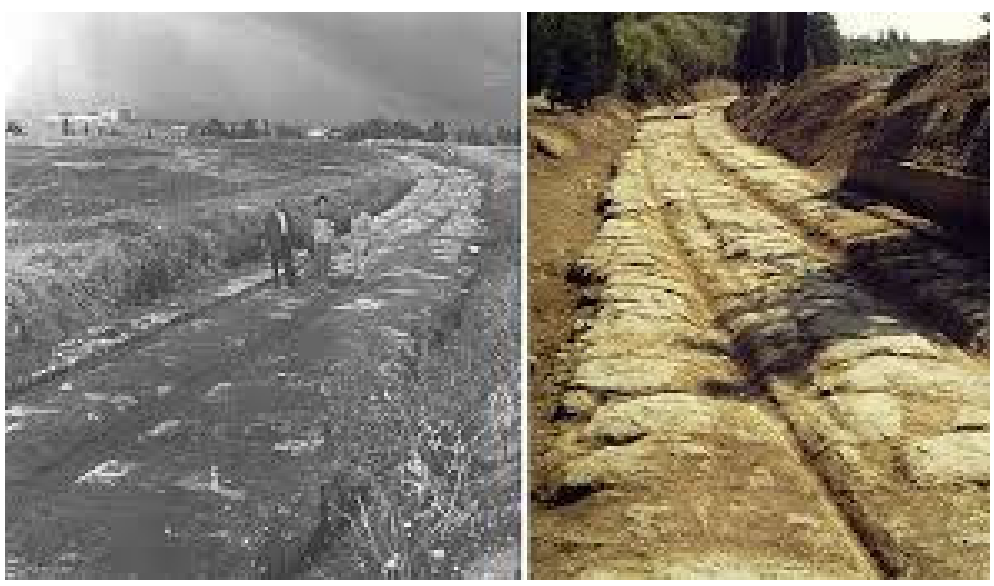

Fig. 1 Ancient Corinthian Diolkos.

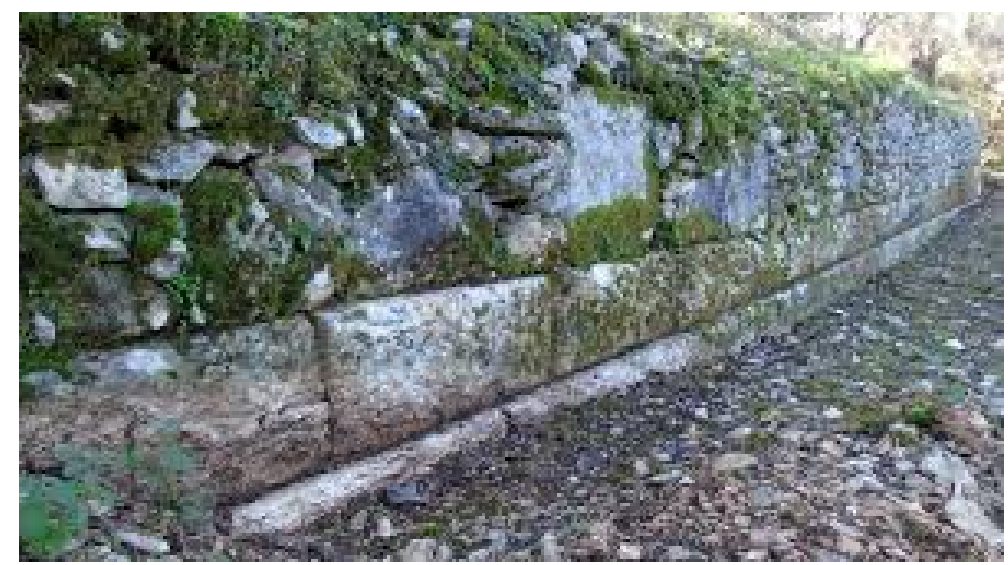

Fig. 2 The wall of the ancient theatre of Lefkada.

noted by ancient sources. In the early part of the 20th century, minimal excavation had taken place under the direction of the German archaeologist E. Kruger, who was a colleague and partner of the archaeologist W. Dörpfeld. The early excavation data were not published, but the excavation diaries and drawings that are available to us today indicate the identification of the ancient theater of Lefkada [7, 9].

\section{Methodological Framework and Data}

\subsection{Methodology}

WTP method is a part of CVM. It is presented an explicitly dynamic methodology of the formation of WTP and WTA and commitment costs under uncertainty and future learning. In this section, authors modify that model to the setting of the special market experiments $[10,11]$.
Consider an interviewee who formulates his WTP or WTA facing a trading opportunity in an experiment, knowing that the same good can be traded in the marketplace $[12,13]$. To add structure, assume that a WTP (WTA) interviewee is one who must state a WTP (WTA) value in an incentive compatible institution. Let $v$ be interviewee's (uncertain) valuation of the good, and let $R$ be his information about the market price of the good. Because ' $v$ ' or ' $R$ ' are not known with certainty, but their distributions are known, it is assumed that the interviewee can learn both ' $v$ ' and ' $R$ ' with certainty later (e.g., after the experiment). So, his WTP is a function of his own valuation about the good, ' $v$ ' and his information about the same good, ' $R$ '.

$$
W T P=F\left(v, R, d_{1}\right)
$$

where $d_{1}$ denotes a group of other deterministic 
variables which can affect the WTP, like age, education level, etc..

Interviewee's valuation about the good $v$ is directly affected by the opportunity cost $O C_{M}$ of the monetary units.

$$
v=F\left(O C_{M}, d_{2}\right)
$$

where $d_{2}$ denotes a group of other deterministic variables which can affect $v$.

It has to be mentioned that the deterministic variables which are included in $d_{1}$ and $d_{2}$ are not the same and actually, they have no variable in common.

A combination of Eqs. (1) and (2) will lead to the fact that WTP is a function of $O C_{M}, R$ and other deterministic parameters with Eq. (3):

$$
W T P=F\left(O C_{M}, R, d\right)
$$

where $=d_{1}+d_{2}$.

The CVM can also be applied to a hypothetical economy with no monetary units, where the trade for goods is time. By asking the interviewees for their WTPar in the restoration of the archaeological site, it is tried to measure the willingness for voluntary participation. So, the opportunity cost of monetary units instantly transforms into opportunity cost of time units $O C_{T}$ and the WTPar function has the following form ceteris paribus.

$$
\text { WTPar }=F\left(O C_{T}, R, d\right)
$$

In present study, the interviewees are soldiers and their opportunity costs of time units are equal to zero due to forbidding of social and paid work by the soldiers.

In order to estimate the Eq. (4), Eq. (5) multi-linear regression is estimated:

$$
z=\beta_{0}+\beta_{1} X_{1}+\cdots+\beta_{k} X_{k}
$$

where the variable $z$ is the dependent variable, while $\beta_{0}$ is the constant term of the regression and $\beta_{1}, \ldots, \beta_{k}$ are the regression coefficients of $X_{1}, \ldots, X_{k}$, respectively. Moreover, the independent variables $X_{j}, j=1,2, \ldots, 8$ stand for respondents' income, age, living distance from the monument, real estate ownership in the vicinity, membership in organization with cultural activities (volunteering), extent to which the interviewee is informed about the history of the site (information), coming in the site as visitors/tourists before (previous visit) and education level, respectively.

After the multi-linear analysis, authors examine the effect of information to WTPar, ceteris paribus. In order to do this, authors firstly applied a Kolomogorov-Smirnov test to secure that authors' data are normally distributed and then authors applied a $t$-test for dependent sample to compare means. In last step of authors' analysis, authors compare WTPar of the interviewees of the present study against the interviewees of a similar study to examine the effect of opportunity cost of their time and information at the same time.

Both researches took place by questionnaires. In first research (about ancient theatre of Lefkada) 100 interviewees were asked to fill a questionnaire about the 8 variables which authors would use and independent variables and about their WTP in order to contribute to the restoration of the theatre. Subsequently, an informative text was given to the same interviewees and they were asked to fill it again. Relative method of data collection was followed to the second research too (about Diolkos). The crucial question authors tried to answer in both researches is if there is a change between the WTP of the interviewees before and after the reading of the informative text, as well as the amount of money they are able to pay.

\subsection{Data Collection and Treatment}

\subsubsection{Diolkos Survey}

In order to collect the data for authors' analysis, authors get a random sample of 100 Greek soldiers who were in the military camp of Corinthos and ask them to complete a questionnaire before they get informed about the monument and the same questionnaire after they read an attached informative text. Authors collect the 100 pairs of questionnaires 
and the above analysis was followed. The same method was followed to collect the pairs of 100 questionnaires about the survey of ancient theatre of Lefkada. In that case, local population and random tourists were asked to fill the questionnaires before and after the reading of an informative text.

The empirical analysis of data from the Diolkos questionnaires was divided into two parts. In the first part, the analysis of variance (AN.O.VA.) and the multi-linear regression model were studied. In the second part, two new variables WTPar1, WTPar2 have been created. WTPar1 represents the soldiers' willingness to participate in the restoration of the monument before they received any information about it. Following the first response, an informative text about the history of the monument was distributed to soldiers and they were asked again about their willingness to participate (WTPar2). Using a $t$-test for paired samples author examine the differentiation between their willingness to participate.

In the first step of analysis author create the WTPar regression which has the Eq. (6):

$$
\text { WTPar }=a+b_{1} X_{1}+\cdots+b_{8} X_{8}+u
$$

where $X_{1}, \ldots X_{8}$ represent the independent variables which were determined in Section 3.

Subsequently, author examine the influence of the independent variables to the dependent one as a group, using the AN.O.VA. approach.

\subsubsection{Lefkada Survey}

In order to complete the research of ancient theatre of Lefkada, authors also asked 100 randomly selected local people to fill a questionnaire before and after the read of an informative test about the benefits of a restoration of a monument of cultural heritage.
The following empirical analysis has exactly the same structure with the research of Corinthian Diolkos. The crucial difference between these researches is the existence of opportunity cost of people who participate in Lefkada's research and the absence of opportunity cost of soldiers who participate in Diolko's research.

\section{Results}

\subsection{Diolkos Survey}

People who were asked to fill the questionnaires in Diolkos survey were soldiers, which means that their age was around 18 years. Specifically, 73 soldiers (not only men) were to the age group of 18-26 and the rest 27 soldiers were above 26 years old. Moreover, 21 soldiers declared that they have primary education, 75 soldiers declared that they are holders of graduation or post-graduation degree and only 4 soldiers declared that they are $\mathrm{PhD}$ candidates.

After the estimation of the simple descriptive statistics authors examined the well-fitting of the model to the theoretical parameters. Specifically, the AN.O.VA. procedure was used for that purpose. The results can be observed in Table 1 .

The $F$-statistic was found equal to 54.152 and also, statistically significant to the $5 \%$ significance level (while the $p$-value is equal to 0.001). According to this result, authors can assume that authors' model is well-structured and the independent variables are appropriate to determine the behavior of the dependent variable. In the next part, Eq. (6) was estimated using a multi-linear regression model. The results of the regression can be seen in Table 2 .

The estimated expression of Eq. (6) has the Eq. (7):

$$
\begin{aligned}
\text { WTPar }=68.2 & -0.013 X_{1}+0.010 X_{2}+0.036 X_{3}+0.011 X_{4}+0.031 X_{5}+0.023 X_{6} \\
+ & 0.013 X_{7}+0.043 X_{8}
\end{aligned}
$$

As it is observed in Table 2 and Eq. (7), all variables have a statistically significant effect on the WTPar variable. More specifically, it is shown that volunteering, age, living distance, ownership, information, previous visit and education level have a positive influence on the soldiers' willingness to 
Table 1 Analysis of variance for dependent variable WTPar (AN.O.VA).

\begin{tabular}{lllll}
\hline Source of variance & Sum of squares & $\mathrm{df}$ & Average sum of squares & $\begin{array}{l}F \text {-statistic } \\
(p \text {-value })\end{array}$ \\
\hline Regression & 48.521 & 8 & 6.065 & 54.152 \\
Residuals & 10.192 & 91 & 0.112 & $(0.001)$ \\
Total & 58.713 & 99 & - & \\
\hline
\end{tabular}

Table 2 Coefficients of multi-linear regression.

\begin{tabular}{ll}
\hline Variable & $\begin{array}{l}\text { Coefficient } \\
(p \text {-value })\end{array}$ \\
\hline$X_{1}$ (Income) & -0.013 \\
& $(0.008)^{*}$ \\
$X_{2}$ (Age) & 0.010 \\
& $(0.037)^{*}$ \\
$X_{3}$ (Living Distance) & 0.036 \\
$X_{4}$ (Ownership) & $(0.018)^{*}$ \\
$X_{5}$ (Volunteering) & 0.011 \\
$X_{6}$ (Information) & $(0.022)^{*}$ \\
$X_{7}$ (Previous Visit) & 0.031 \\
$X_{8}$ (Education Level) & $(0.007)^{*}$ \\
\hline
\end{tabular}

* denotes statistical significance at $5 \%$.

participate in the restoration of "Diolkos", while the income effect on same variable seems to be negative. Despite the fact that the effect of each variable seems to be low enough to change the maximum time of voluntary supply work of soldiers on its own, the aggregate effect of all variables seems to be able to cause a statistically significant change on WTPar time of soldiers.

In the second part, WTPar1 and WTPar2 were created according to the procedure presented in the section of methodology. The descriptive statistics and a bar-chart of these two variables can be observed in Table 3, Fig. 2 and Fig. 3 respectively.

The mean of WTPar1 is equal to 1.50 , while the mean of WTPar2 is more than three times higher and equal to 4.58. This result can also be visualized by the bar-chart. Consequently, it can be seen that there is a significant difference between these variables. To validate this, $t$-test for paired samples was used to compare the means of WTPar1 and WTPar2 time of soldiers before and after they received some information about Diolkos monument. In order to choose a proper parametric or non-parametric test, a Kolmogorv-Smirnov test was first applied in order to examine if data are normally distributed. The test was positive, and allowed the use of a $t$-test for dependent samples to compare means of WTPar1 and WTPar2. The results of this test are given below in Table 4 .

The results of the analysis show statistical significant difference between WTPar1 and WTPar2 while the $t$-statistic was found equal to -57.146 with respective $p$-value equal to 0.000 . So, there is significant difference between the time soldiers are available to spend on the restoration before and after information supply. This result is an indication of soldiers' sensitization to restore monuments of Greek cultural heritage if they are aware about the history of the monuments.

\subsection{Lefkada Survey}

A sample of 100 interviewees were selected and their willingness to participate in the excavation of the 
Table 3 Descriptive statistics for WTPar1, WTPar2.

\begin{tabular}{lllllll}
\hline Variable & $N$ & Mean & $S D$ & SE mean & Min. & Max. \\
\hline WTPar1 & 100 & 1.50 & 0.89 & 0.150 & 0.00 & 10.00 \\
WTPar2 & 100 & 4.58 & 0.12 & 0.430 & 1.00 & 12.00 \\
\hline
\end{tabular}

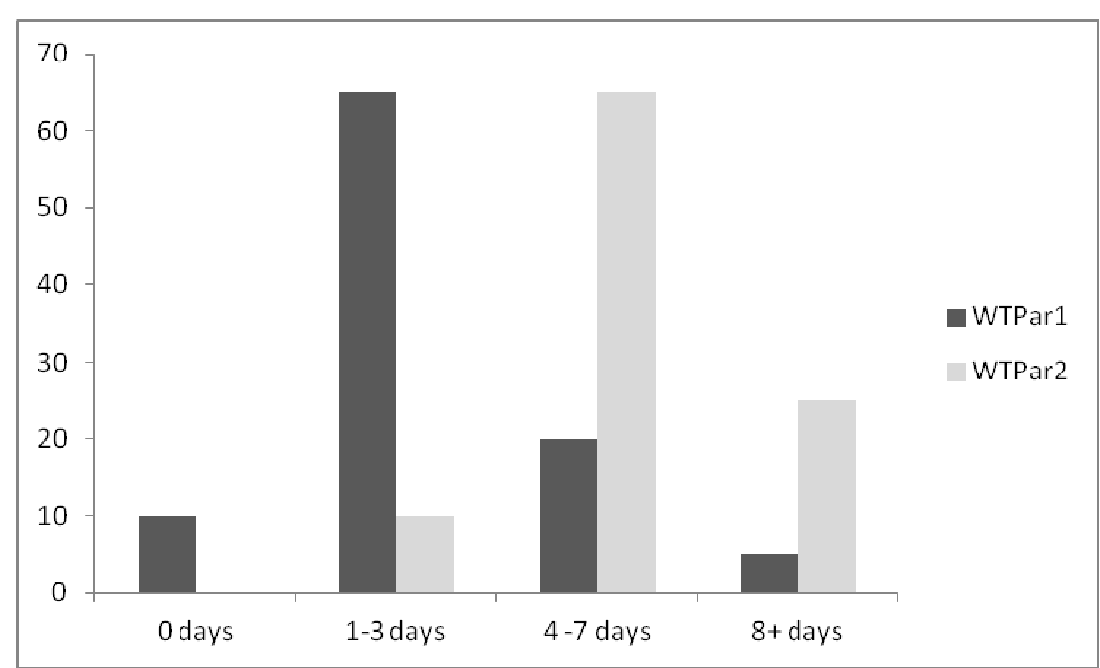

Fig. 3 Comparing WTPar1 and WTPar2 after grouping them in appropriate classes.

Table 4 t-test for paired samples.

\begin{tabular}{|c|c|c|c|c|c|}
\hline Pair of variables & Mean & Standard deviation & $t$-statistic & $p$-value & Decision \\
\hline $\begin{array}{l}\text { WTPar1 - } \\
\text { WTPar2 }\end{array}$ & -0.97 & 0.170 & -57.146 & 0.000 & $\begin{array}{l}\text { Significant difference before } \\
\text { and after information }\end{array}$ \\
\hline
\end{tabular}

Table 5 Descriptive statistics of WTPar in two monuments.

\begin{tabular}{llllll}
\hline WTPar1-Before information & $\mathrm{N}$ & Mean & SD & Min. & Max. \\
\hline Monument & 100 & 0.50 & 1.451 & 0.00 & 6.00 \\
\hline Lefkada's Theatre & 100 & 1.50 & 0.89 & 0.00 & 10.00 \\
Corinthian Diolkos & 100 & & & & 9.00 \\
\hline WTPar2-After information & 4.13 & 2.899 & 1.00 & 12.00 \\
\hline Lefkada's Theatre & 100 & 4.58 & 0.12 & 1.00 & \\
Corinthian & & & & \\
Diolkos & &
\end{tabular}

Table $6 t$-test for independent samples for WTPar for two monuments before and after information.

\begin{tabular}{llllll}
\hline Before information & \multicolumn{5}{l}{} \\
\hline Pair of variables & Mean & Standard deviation & $t$-statistic & $p$-value & Decision \\
\hline $\begin{array}{l}\text { WTPar1 (Theatre) - } \\
\text { WTPar1 (Diolkos) }\end{array}$ & -1.00 & 0.567 & -19.111 & 0.001 & $\begin{array}{l}\text { Significant } \\
\text { difference }\end{array}$ \\
\hline After information & & & & \\
\hline $\begin{array}{l}\text { WTPar2 (Theatre) - } \\
\text { WTPar2 (Diolkos) }\end{array}$ & -0.45 & 0.037 & 0.713 & 0.219 & $\begin{array}{l}\text { No significant } \\
\text { difference }\end{array}$ \\
\hline
\end{tabular}

ancient theatre of Lefkada Island in Greece is estimated before and after reading of an informative text about this monument. The main difference between the two studies is the existence (Lefkada) and the absence (Diolkos) of opportunity cost of the interviewees. So, a comparison between both ancient cultural heritage monuments would be interesting. In Table 5, the descriptive statistics of both studies are compared.

The important effect of opportunity cost in WTPar is obvious according to the above descriptive statistics. 
People with opportunity cost are able to spend an average of half a day on the restoration of the monument against an average of 1.5 days by people without opportunity cost of labor before information.

A significant increase of these averages can be observed after the information, with 4.13 days and 4.58 days respectively. To examine if there are significant differences between the WTPar of interviewees of each group, $t$-test was performed for independent samples before and after information supply. The results can be seen in Table 6 .

Table 6 provides evidence for significant difference between WTPar1 for each monument which declares that the existence of opportunity cost of labor affects the willingness of interviewees to participate in restoration of these cultural heritage monuments. It also provides evidence for no difference between WTPar2 for each monument which is a very interesting finding because it allows assuming that the effect of information to WTPar is much stronger than the effect of opportunity cost.

\section{Conclusion and Discussion}

The effect of opportunity cost to the validity of CVM for cultural heritage has been studied herein using an ancient Greek monument called "Diolkos" and interviewees serving in a near-by military camp. The survey used two runs: one questionnaire without providing any information for monument and one after the distribution of information leaflets.

The soldiers' willingness to participate in the restoration of "Diolkos" is influenced by several parameters: income, age, educational level, living distance, ownership, volunteering, information and previous visiting. Soldiers with higher education level showed greater willingness to participate than those with lower education level. Moreover, the older the soldier was the greater willingness to participate he stated. In addition, the distance of permanent residence from the monument, the previous visits to the monument and the ownership of any kind of land around the monument had a positive influence on the willingness of soldiers. An extremely interesting result is the positive effect of information on the soldiers' willingness. A significant increase of their willingness was observed after they had been informed about the history of "Diolkos". The negative income effect to the soldiers' willingness to participate is another interesting result of authors' analysis. The summary of results above can be seen in Table 5 and Table 7.

The fact of negative income effect is explained through the refusing of soldiers with higher family income to participate in the restoration of "Diolkos". It seems that the higher income a person has, the less willing is to get personally involved. An absolute opposite effect is seen in the volunteers and informed. A person with previous volunteering activity seems to be more concerned and sensitized to cultural heritage monuments. The awareness of this population about the level of usefulness of voluntary work drives them to continuously try to offer more and more voluntary work. An extremely interesting and positive effect on the willingness is coming from the awareness of the participants. The more knowledge a person has about a monument the higher his willingness to participate in its restoration. In effect, knowledge raises the value of the monument manifold. Consequently, the main result of Diolko's research is that information and personal interest are two great "powers" of nowadays. The higher education level and study about a crucial subject a person has, the higher sensitivity he has.

Table 7 Effect of several parameters to the willingness to participate.

\begin{tabular}{lc}
\hline Parameter & Effect \\
Income & - \\
Education level & $\mathbf{t}$ \\
Information & $\mathbf{+}$ \\
Volunteering & $\mathbf{+}$ \\
Ownership & $\mathbf{+}$ \\
Age & $\mathbf{+}$ \\
Previous visit & $\mathbf{+}$ \\
Living distance & $\mathbf{+}$ \\
\hline
\end{tabular}


In comparison, the willingness of interviewees to participate in the restoration of the ancient theatre of Lefkada Island in Greece was estimated with the traditional method. The difference between the two studies is the existence of opportunity cost in the first study and its absence in the second. According to the Lefkada survey, the $58 \%$ of interviewees have previously volunteered in similar works, whereas $42 \%$ have not; the $36 \%$ of the interviewees had visited the site, while $64 \%$ had not; the $31.5 \%, 41 \%$ and $27.5 \%$ of the interviewees were aged between 18-22, 23-47 and 28-31 years old, respectively. The 3\%, 22\%, $31.5 \%, 22 \%$ and $21.5 \%$ of the interviewees have completed primary school, high school (1-3 class), high school (4-6 class), university or technological institution or postgraduate studies respectively.

The difference between the willingness to participate in voluntary work seems to be higher before the distribution of the information leaflet. Similarly to the Diolkos survey, the willingness to volunteer is substantially increased after the interviewees learnt the history of the monument. Evidently, the effect of the opportunity cost is counterbalanced by the information effect.

The output of the WTP approach is the demand curve of a non-marketable good. The methodological modification presented herein leads to the extraction of a supply curve for voluntary work. This is particularly interesting and quite straightforward because the participants have no opportunity cost and no income during their military service. Moreover, there is not a transportation cost to consider, because the interviewees are located at the site. The outcome of this method might be inconclusive when these variables, i.e., opportunity cost of time and transportation cost, have to be considered.

The depreciation of antiquities caused by humans is an external economy, which is not corrected through any institution or market. From the statistical analysis provided herein, a path is clearly drawn to stabilize the social costs of depreciation of cultural goods. External effects are observed when supply or demand impose costs or confer a benefit to others. The external effect is the impact of the behaviour of a producer or consumer well-being of another, which is not reflected in market transactions. The external effect of the deterioration of cultural monuments is universal and appears as an external benefit borne by all of humanity through time.

\section{References}

[1] Alberini, A., Boyle, K., and Welsh, M. 2003. "Analysis of Contingent Valuation Data with Multiple Bids and Response Options Allowing Respondents to Express Uncertainty." Journal of Environmental Economics and Management 45 (1): 40-62.

[2] Báez-Montenegro, A., Bedate, A., Herrero, L., and Sanz, J. 2012. "Inhabitants' Willingness to Pay for Cultural Heritage: A Case Study in Valdivia, Chile, Using Contingent Valuation." Journal of Applied Economics 15 (2): 235-58.

[3] Bateman, I., Munro, A., Rhodes, B., Starmer, C., and Sugden, R. 1997. "A Test of the Theory of Reference-Dependent Preferences." The Quarterly Journal of Economics 112: 479-505.

[4] Bedate, A., Herrero, L., and Sanz, J. 2009. "Economic Valuation of a Contemporary Art Museum: Correction of Hypothetical Bias Using a Certainty Question." Journal of Cultural Economics 33 (3): 185-99.

[5] Bedate, A., Herrero, L. C., and Sanz, J. A. 2005. "Economic Valuation of the Cultural Heritage: Application to Four Case Studies in Spain.” Journal of Cultural Heritage 5 (1): 101-11.

[6] Brown, T. C. 2005. "Loss Aversion without the Endowment Effect, and Other Explanations for the WTA-WTP Disparity." J. Econ. Behav. Org. 57 (3): 367-79.

[7] Lo, A. Y., and Jim, C. Y. 2015. "Protest Response and Willingness to Pay for Culturally Significant Urbantrees: Implications for Contingent Valuation Method." Ecol. Econ. 114: 58-66.

[8] Hanemann, W. M. 1991. "Willingness to Pay and Willingness to Accept: How Much Can They Differ?" American Economic Review 81 (3): 635-47.

[9] Menard, S. 2001. Applied Logistic Regression Analysis (2nd ed.). LA: SAGE Publications Inc..

[10] Herrero, L., Sanz, J., and Devesa, M. 2011. "Measuring the Economic Value and Social Viability of a Cultural Festival as a Tourism Prototype.” Tourism Economics 17 
(3): 639-53.

[11] Horowitz, J. K., and McConnell, K. E. 2003. "Willingness to Accept, Willingness to Pay and the Income Effect." Journal of Economic Behavior and Organization 51 (4): 537-45.

[12] Lee, C., and Han, S. 2002. "Estimating the Use and
Preservation Values of National Parks' Tourism Resources Using a Contingent Valuation Method." Tourism Management 23 (5): 531-40.

[13] Liao, T. F. 1994. Interpreting Probability Models: Logit, Probit, and Other Generalized Linear Models. LA: SAGE Publications Inc.. 